\title{
PENGARUH PENERAPAN STRATEGI PEMBELAJARAN EXAMPLE NON EXAMPLE PADA PEMBELAJARAN MATEMATIKA SEKOLAH DASAR
}

\author{
Sahrun Nisa \\ Pendidikan Dasar, Sekolah Pascasarjana Universitas Pendidikan Indonesia \\ Email : sahrun@upi.edu
}

\begin{abstract}
Abstrak. Peneitian ini didasari bahwa siswa sekolah dasar masih dalam taraf berfikir operasional konkrit. Oleh karena itu dibutuhkan suatu strategi yang dapat menjembatani antara taraf berfikir siswa dengan sifat matematika yang abstrak. Penelitian ini bertujuan untuk mengetahui besar pengaruh antara pembelajaran dengan model Problem Based Learning (PBL) dengan pembelajaran yang menggunakan model PBL dengan strategi Example Non Example. Populasi dari penelitian ini adalah siswa kelas IV SD dengan sampel sebanyak 25 orang siswa dikelas ekperimen dan 28 orang siswa di kelas kontrol. Hasil dari penelitian ini adalah terdapat perbedaan yang signifikan antara siswa yang dibelajarkan pada model PBL menggunakan strategi Example Non Example dengan siswa yang hanya dibelajarkan dengan model PBL saja. Besar pengaruh ditinjau dari rata - rata hasil belajar sebesar 21,64 \%. Siswa dikelas yang belajar dengan model PBL strategi Example Non Example juga lebih aktif terlibat dalam pembelajaran dibandingkan dengan model PBL.
\end{abstract}

Kata Kunci : Example Non Example, Problem Based Learning (PBL), Pembelajaran Matematika SD

\section{PENDAHULUAN}

Matematika merupakan salah satu ilmu pengetahuan universal yang melatarbelakangi berkembangnya ilmu pengetahuan dan teknologi. Esensi dari matematika inilah yang menjadikan sejak sekolah dasar pembelajaran matematika telah diberikan. Namun, sifat abstrak matematika bertolak belakang dengan proses berfikir siswa Sekolah Dasar (SD). Siswa SD umumnya berumur sekitar dimulai dari 6 atau 7 tahun sampai 12 atau 13 tahun. Menurut Piaget, mereka yang berada dalam umur ini masih dalam fase berfikir operasional konkret. Kemampuan yang tampak pada fase ini adalah kemampuan dalam proses berfikir untuk mengoperasikan kaidah-kaidah logika, meskipun masih terikat dengan objek yang bersifat konkret (Heruman, $2008 \mathrm{hlm} .1$ ).

Hasil belajar siswa Sekolah Dasar Negeri (SDN) 4 Minas Timur, masih belum menunjukkan hasil yang memuaskan. Hasil ujian semester I siswa dapat dilihat pada tabel berikut :

Tabel 1. Hasil Belajar Siswa Kelas IV SDN 4 Minas Timur Semester 1 T.P.2017/2018

\begin{tabular}{ccc}
\hline Kelas & Rata-rata & Predikat \\
\hline IV A & 78.12 & $\mathrm{C}$ \\
IV B & 77.03 & $\mathrm{C}$ \\
\hline
\end{tabular}

Rendahnya hasil belajar siswa salah satunya disebabkan oleh lemahnya pemahaman siswa terhadap konsep - konsep yang dipelajari siswa. Berdasarkan hasil wawancara peneliti dengan guru kelas, guru cenderung masih menggunakan model pembelajran ekspositori dengan strategi yang dimana menurut guru nyaman untuk siswa belajar. Kurangnya guru memberi kesempatan kepada siswa untuk mengeksplorasi sendiri materi membuat siswa cenderung hanya menerima pelajaran tanpa memahami dan memaknai apa yang dipelajarnya. Disisi lain, pengelolaan pembelajaran dalam Kurikulum 2013 lebih mengutamakan model pembelajaran discovery, Problem Based Learning (PBL) dan Project Based Learnig (PjBL) karena ketiga model pembelajaran sejalan dengan pembelajaran saintifik. Model pembelajaran PBL adalah model pembelajaran yang cocok digunakan disekolah dasar karena PBL berangkat dari penyajian kepada siswa situasi yang autentik (nyata) dan bermakna bagi siswa. Menurut Arends, PBL adalah suatu pendekatan pembelajaran dimana siswa mengerjakan permasalahan yang autentik dengan maksud menyusun pengetahuan mereka sendiri, mengembangkan inkuiri dan keterampilan berpikir lebih tinggi, mengembangkan kemandirian dan percaya diri (Trianto, 2012, hlm.91).

Konsep - konsep kurikulum dalam matematika di sekolah dasar dapat dibagi tiga yaitu penanaman konsep dasar, pemahaman konsep dan pembinaan keterampilan. Penanaman konsep dasar harus tercapai agar dua konsep kurikulum lainnya dapat dicapai. Penanaman konsep dasar ditandai dengan kata "mengenal" dalam kompetensi yang harus dicapai siswa. Dalam usia perkembangan kognitif siswa SD penanaman konsep pada siswa sekolah dasar dapat 
tercapai jika konsep masih terikat dengan objek konkret yang masih bisa ditangkap oleh panca indera. Oleh karena itu, perlu perantara media sebagai alat bantu untuk menggambarkan dan memperjelas apa yang disampaikan oleh guru sehingga lebih cepat dipahami oleh siswa (Heruman, $2008 \mathrm{hlm}$. 1). Salah satu media yang dapat digunakan adalah gambar.

Media gambar dapat digunakan untuk menggambarkan model dari wujud abstrak matematika, terutama dalam lingkup materi geometri, untuk meningkatkan pemahaman siswa. Menurut Wijaya dalam Astuty (Susanti, 2014) media berperan sebagai perangsang belajar dan dapat menumbuhkan motivasi belajar sehingga siswa tidak menjadi bosan dalam meraih tujuan - tujuan belajar. Dalam pembelajaran, media memiliki fungsi antara lain: mengatasi hambatan proses komunikasi, sikap pasif siswa dalam belajar dan mengatasi keterbatasan fisik siswa Salah satu indikator siswa paham matematika menurut NCTM (1989, hlm 223) adalah kemampuan siswa mengidentifikasi dan membuat contoh dan bukan contoh. Oleh karena itu, salah satu strategi yang dapat digunakan dengan media gambar adalah strategi Example Non Example.

Strategi Example non Example adalah strategi yang menggunakan perbandingan gambar contoh dan bukan contoh terhadap ciri-ciri suatu konsep. Contohcontoh dapat diperoleh dari kasus/gambar yang relevan dengan kompetensi dasar (Yensi, 2012). Suyatno (Km. Wardika, 2014) menyatakan Examples non examples mendorong siswa untuk belajar lebih kritis dengan jalan memecahkan permasalahan - permasalahan yang terkandung dalam contoh-contoh gambar yang disediakan. Penggunaan model pembelajaran examples non examples lebih mengutamakan konteks analisis siswa, karena konsep yang diajarkan diperoleh dari hasil penemuan dan bukan berdasarkan konsep yang terdapat dalam buku. Dengan memusatkan perhatian siswa terhadap examples non examples diharapkan dapat mendorong siswa untuk menuju pemahaman yang lebih dalam terhadap materi pelajaran.

Berangkat dari uraian diatas, maka penelitian ini bertujuan untuk melihat pengaruh strategi Example Non Example terhadap pembelajaran matematika dengan menggunakan model pembelajaran PBL.

\section{METODE}

Penetian dilaksanakan di SD Negeri 4 Minas Timur, Kabupaten Siak, Propinsi Riau pada tanggal 5 9 Januari 2018. Metode yang digunakan dalam penelitian ini adalah Kuasi Eksperimen dengan desain Nonequivalent Intact-Group Comparison dengan gambaran sebagai berikut :

$\begin{array}{ll}\mathrm{X} & \mathbf{O}_{1} \\ & \mathbf{O}_{2}\end{array}$

Dengan besar pengaruh $=\mathrm{O}_{1}-\mathrm{O}_{2}$ (Sugiyono, 2011)

Populasi Penelitian adalah siswa kelas IV SD Negeri 4 Minas Timur. Teknik sampling yang digunakan adalah purposive sampling dimana dipilih sampel kelas IV A sebagai kelas eksperimen $\left(\mathrm{O}_{1}\right)$ dan kelas IV B $\left(\mathrm{O}_{2}\right)$ sebagai kelas kontrol. Kelas eksperimen diberi perlakuan model pembelajaran PBL dengan strategi Example Non Example dan kelas kontrol diberi perlakuan model pembelajaran PBL. Sampel berjumlah 53 orang dengan rincian kelas eksperimen sebanyak 28 orang dan kelas kontrol sebanyak 25 orang.

Instrumen yang digunakan untuk mengumpulkan data yaitu tes. Tes penanaman konsep matematis pada indikator mengenal bentuk segi banyak diberikan kepada kelas eksperimen dan kelas kontrol, sesudah perlakuan (posttest). Tes berbentuk soal uraian (essay) sebanyak 3 soal. Data selanjutnya diolah dengan menggunakan statistik inferensial dengan bantuan SPSS versi 24 dengan nilai signifikasi sebesar 0,05 .

\section{HASIL DAN PEMBAHASAN Deskripsi Hasil Penelitian}

Data yang dideskripsikan pada bagian ini adalah hasil tes penanaman konsep pada konsep pengenalan segi banyak. Pada indikator pertama, siswa mampu membedakan antara segi banyak dan bukan segi banyak. Pada indikator kedua, siswa mampu membedakan antara segi banyak beraturan dan segi banyak tidak beraturan dan pada indikator ketiga siswa mampu membuat contoh antara segi banyak beraturan dan segi banyak tidak beratran. Secara deskriptif, hasilya adalah sebagai berikut

Tabel 2. Statistik Deskriptif Hasil Penelitian

\begin{tabular}{lcccc}
\hline & Guup & N & Mean & SD \\
\hline Nilai_Total & Eksperimen & 28 & 80.45 & 14.58 \\
\cline { 2 - 5 } & Kontrol & 25 & 58.81 & 12.16 \\
\hline Nilai_Ind 1 & Eksperimen & 28 & 83.03 & 12.10 \\
\cline { 2 - 5 } & Kontrol & 25 & 75.99 & 13.67 \\
\hline Nilai_Ind 2 & Eksperimen & 28 & 76.19 & 18.82 \\
\cline { 2 - 5 } & Kontrol & 25 & 52.44 & 16.52 \\
\hline Nilai_Ind 3 & Eksperimen & 28 & 82.14 & 33.23 \\
\cline { 2 - 5 } & Kontrol & 25 & 48.00 & 25.94 \\
\hline
\end{tabular}

Selanjutnya, untuk melihat apakah data berdistribusi normal atau tidak, maka akan dilakukan uji normalitas. Tujuannya adalah untuk menetukan apakah perbandingan rataan akan menggunakan statistic parametric atau non parametric. Adapun hasinya adalah sebagai berikut : 
PRINSIP Pendidikan Matematika

Volume 1, Nomor 1, November 2018

Tabel 3. Hasil Uji Normalitas

\begin{tabular}{lcccc}
\hline \multirow{2}{*}{ Grup } & \multicolumn{3}{c}{ Shapiro-Wilk } \\
\cline { 3 - 5 } & & Statistic & df & Sig. \\
\hline \multirow{2}{*}{ Nilai_Total } & Eksperimen & .907 & 28 & .017 \\
\cline { 2 - 5 } & Kontrol & .942 & 25 & .165 \\
\hline Nilai_Ind1 & Eksperimen & .922 & 28 & .039 \\
\cline { 2 - 5 } & Kontrol & .831 & 25 & .001 \\
\hline Nilai_Ind2 & Eksperimen & .900 & 28 & .012 \\
\cline { 2 - 5 } & Kontrol & .899 & 25 & .018 \\
\hline Nilai_Ind3 & Eksperimen & .589 & 28 & .000 \\
\cline { 2 - 5 } & Kontrol & .758 & 25 & .000 \\
\hline
\end{tabular}

Dari Tabel 3 dapat dilihat bahwa seluruh data tidak berdistribusi normal kecuali pada nilai keseluruhan di kelas kontrol. Karena tidak ada data pasangan yang berdistribusi normal, maka tidak ada data yang bervariansi homogen. Oleh karena itu akan dilakukan uji non parametrik Mann-Withney. Adapun hasilnya adalah sebagai berikut :

Tabel 4. Hasil Tes Mann-Withney

\begin{tabular}{|c|c|c|c|c|c|}
\hline & Null Hypothesis & Test & & Sig. & Decision \\
\hline 1 & $\begin{array}{l}\text { The distribution of Nilai_Total } \\
\text { is the same across categories } \\
\text { of Group }\end{array}$ & $\begin{array}{l}\text { Independent } \\
\text { Samples } \\
\text { Mann- } \\
\text { Whitney } \\
\text { Test }\end{array}$ & $\mathrm{U}$ & .000 & $\begin{array}{l}\text { Reject the } \\
\text { null } \\
\text { hypothesis }\end{array}$ \\
\hline 2 & $\begin{array}{l}\text { The distribution of Nilai_1 is } \\
\text { the same across categories of } \\
\text { Group }\end{array}$ & $\begin{array}{l}\text { Independent } \\
\text { Samples } \\
\text { Mann- } \\
\text { Whitney } \\
\text { Test }\end{array}$ & U & .080 & $\begin{array}{l}\text { Retain the } \\
\text { null } \\
\text { hypothesis }\end{array}$ \\
\hline \multirow[t]{2}{*}{3} & \multirow[t]{2}{*}{$\begin{array}{l}\text { The distribution of Nilai_2 is } \\
\text { the same across categories of } \\
\text { Group }\end{array}$} & $\begin{array}{l}\text { Independent } \\
\text { Samples } \\
\text { Mann- } \\
\text { Whitney } \\
\text { Test }\end{array}$ & $\mathrm{U}$ & .000 & $\begin{array}{l}\text { Reject the } \\
\text { null } \\
\text { hypothesis }\end{array}$ \\
\hline & & $\begin{array}{l}\text { Independent } \\
\text { Samples } \\
\text { Mann- } \\
\text { Whitney } \\
\text { Test }\end{array}$ & $\mathrm{U}$ & .000 & $\begin{array}{l}\text { Reject the } \\
\text { null } \\
\text { hypothesis }\end{array}$ \\
\hline
\end{tabular}

Dari hasil tabel 4 diatas dapat terlihat bahwa secara keseluruhan terdapat perbedaan hasil belajar antara kelas yang diberi perlakuan dengan yang tidak diberi perlakuan. Adapun besar pengaruhnya ditinjau dari rata-ratanya yaitu $21,64 \%$.

Pada indikator 1 secara statistik terbukti bahwa tidak ada perbedaan hasil belajar penanaman konsep membedakan segi banyak dan bukan segi banyak baik dengan perlakuan atau tidak dengan perlakuan. Pada indikator kedua, terbuti bahwa terdapat perbedaan hasil belajar membedakan segi banyak beraturan dan segi banyak tidak beraturan pada kelas eksperimen da kelas kontrol. Adapun besar pengarunya sebesar $23.75 \%$.
Sedangakan pada indikator terakhir yaitu membuat contoh segi banyak beraturan dan segi banyak tidak beraturan terdapat perdedaan yang signifikan antara kelas yang diberi perlakuan dengan kelas yang tidak diberi perlakuan. Perbedaan pengaruhnya sebesar 44.14 $\%$

\section{Pembahasan}

Berdasarkan hasil penelitian diatas, dapat terlihat bahwa strategi Example Non Examples memberikan pengaruh yang signifikan terhadap pembelajaran yang menggunakan model pembelajaran Problem Based Learning (PBL). Secara keseluruhan, ditinjau dari ratarata hasil belajar, strategi Example Non Example memberikan pengaruh positif ditandai dengan nilai perbedaan pengaruh yang positif. Hal ini sejalan dengan beberapa hasil penelitian sebelumnya seperti Djafar (2014), Wardika, dkk (2014), Susanti (2014) dan Yensi (2012) walaupun hasil penelitian sebelumnya belum meneliti tentang pembelajaran matematika di sekolah dasar.

Hasil belajar pada indikator 1 tidak terdapat perbedaan yang signifikan antara siswa yang belajar dengan Model PBL dengan strategi Example Non Example dengan siswa yang dibelajarkan dengan Model PBL. Sewaktu pembelajaran mengenal bentuk segi banyak, guru memulai pembelajaran dikedua kelas dengan hal yang sama, yaitu mendorong siswa untuk melihat seisi kelasnya kemudian menyebutkan bentuk dari benda - benda tersebut. Strategi Example Non Example mulai dilaksanakan ketika membandingkan antara jam dinding (lingkaran) dengan pintu kelas (persegi panjang) sementara di kelas kontrol hanya mengelaborasi pintu kelas saja.

Hasil belajar dari indikator dua menunjukkan adanya perbedaan antara kelas kontrol dan kelas eksperimen. Pada saat pembelajaran dikelas eksperimen, guru membandingkan antara bentuk layangan Wau (layangan melayu) sebagai bukan contoh dengan logo Kementrian Agama sebagai contoh, sedangkan di kelas kontrol, guru mendorong siswa mengamati logo Kementrian Agama. Siswa di kelas eksperimen dan di kelas kontrol sama-sama di beri dorongan bagimana penamaan segi banyak, namun siswa di kelas eksperimen lebih memahami karena langsung membandingkan antar bentuk segi banyak sedangkan di kelas kontrol tidak.

Akibat dari hasil belajar pada indikator 2, pada indikator 3 juga menunjukkan adanya perbedaan yang signifikan hasil belajar antara kelas eksperimen dan kelas kontrol. Pada indikator 3, kreativitas siswa dalam membuat segi banyak tidak beraturan dapat terlihat. Untuk menggambar segi enam tidak beraturan, kedua 
kelas dapat menggambarkannya dengan sangat baik dengan bentuk yang bermaca-macam pula. Berbeda dengan gambar model segi banyak beraturan. Pada kelas kontrol, hanya dua orang siswa yang berhasil membuat gambar segi banyak beraturan sedangkan di kelas eksperimen, hampir seluruh siswa memahami bagaimana membuat model segi banyak beraturan.

Secara keseluruhan, aktivitas pembelajaran di kelas eksperimen lebih aktif dari pada di kelas kontrol, hal ini disebabkan dorongan siswa yang harus membandingkan contoh dan bukan contoh untuk mendefinisikan ciri - ciri segi banyak. Siswa di kelas eksperimen terlihat salng berdiskusi dengan teman dikelompoknya untuk memberikan pendapat. Pembelajaran dikelas kontrol sedikit pasif dibandingkan dikelas eksperimen. Walaupun siswa mampu menyampaikan pendapatnya, namun siswa masih terlihat bingung untuk menyampaikan pendapatnya. Sehingga peran guru dalam meluruskan maksud peserta didik sangat diperlukan.

\section{SIMPULAN}

Penelitian menunjukkan perbedaan yang signifikan antara siswa yang dibelajarkan dengan model pembelajaran Problem Based Learning (PBL) dengan strategi Example non Example dengan siswa yang dibelajarkan dengan model PBL saja. Besar perbedaan pengaruh ditinjau dari rata-rata hasil belajar secara keseluruhan sebesar 21,64\%. Hal ini sejalan dengan beberapa penelitian sebelumnya yang dilaksanakan di mata pelajaran lain dan tingkatan sekolah lain. Aktivitas belajar siswa dikelas yang dibelajarakan pada model pembelajaran PBL dengan strategi Example Non Example juga lebih aktif dibandingkan dengan siswa yang dibelajarkan degan model pembelajaran PBL saja.

Strategi Example Non Example dapat dijadikan salah satu alternatif dalam pembelajaran terutama dalam pembelajaran di kurikulum 2013. Strategi ini dapat digunakan untuk mendorong siswa agar siswa lebih aktif terlibat dalam pembelajaran. Selanjutnya peneliti mengharapkan adanya penelitian lebih lanjut terhadap penggunaan strategi ini untuk kelas rendah karena strategi ini sangat membantu siswa untuk melihat bentuk - bentuk konkret sebelum masuk dalam bentuk abstrak matematis.

\section{DAFTAR PUSTAKA}

Djafar, N. A. (2014). Penerapan Model Pembelajaran Example Non Example Untuk Meningkatkan Kemampuan Berpikir Kritis Peserta Didik Kelas VIII.K SMP Negeri 4 Sungguminasa Kabupaten Gowa. Jurnal Bionature, 67-80.

Heruman. (2008). Model Pembelajaran Matematika di Sekolah Dasar. Bandung: PT. Remaja Rosdakarya.

Km. Wardika, M. S. (2014). Pengaruh Model Examples Non Example Terhadap Hasil Belajar IPA Siswa Kelas V SD di Gugus III Kecamatan Tampaksiring. Jurnal Mimbar PGSD Undiksha, 1-10.

NCTM. (1989). Curriculum and Evaluation Standards for School Mathematics. Reston, VA: NCTM.

Sugiyono. (2011). Metode Penelitian Pendidikan. Bandung: CV. Alfabeta.

Susanti, R. (2014). Pembelajaran Model Example Non Examples Berbantuan Powerpoint untuk Meningkatkan Hasil Belajar IPA. Jurnal Pendidikan IPA Indonesia, 123-127.

Trianto. (2012). Mendesain Model Pembelajaran Inovatif-Prgresif. Jakarta: Kencana Predana Media Group.

Yensi, N. A. (2012). Penerapan Pembelajaran Kooperatif Tipe Examples Non Examples dengan Menggunakan Alat Peraga untuk Meningkatkan Hasil Belajar Siswa di Kelas VIII SMP N 1 Argamakmur. Jurnal Exacta, 24-35. 